\title{
Predicting acute kidney injury: current status and future challenges
}

\author{
Simona Pozzoli ${ }^{1} \cdot$ Marco Simonini $^{1} \cdot$ Paolo Manunta $^{1}$
}

Received: 2 December 2016 / Accepted: 27 May 2017 / Published online: 17 June 2017

(c) The Author(s) 2017. This article is an open access publication

\begin{abstract}
Acute kidney injury (AKI) is characterized by an acute decline in renal function and is associated to increased mortality rate, hospitalization time, and total health-related costs. The severity of this 'fearsome' clinical complication might depend on, or even be worsened by, the late detection of AKI, when the diagnosis is based on the elevation of serum creatinine ( $\mathrm{SCr}$ ). For these reasons, in recent years a great number of new tools, biomarkers and predictive models have been proposed to clinicians in order to improve diagnosis and prevent the development of AKI. The purpose of this narrative paper is to review the current state of the art in prediction and early detection of AKI and outline future challenges.
\end{abstract}

Keywords Acute kidney injury · Prediction ·

Biomarkers $\cdot$ Genetics $\cdot$ New OMICs

$\begin{array}{ll}\text { Abbreviations } \\ \text { AKI } & \text { Acute kidney injury } \\ \text { ATN } & \text { Acute tubular necrosis } \\ \text { AUC } & \text { Area under the curve } \\ \text { BUN } & \text { Blood urea nitrogen } \\ \text { CKD } & \text { Chronic kidney disease } \\ \text { CYC-C } & \text { Cystatin-C } \\ \text { eGFR } & \text { Estimated glomerular filtration rate } \\ \text { EO } & \text { Endogenous ouabain } \\ \text { FABPs } & \text { Fatty acid-binding proteins } \\ \text { FFAs } & \text { Free fatty acids }\end{array}$

Marco Simonini

simonini.marco@hsr.it

1 Chair of Nephrology - IRCCS San Raffaele Scientific Institute, Genomics of Renal Diseases and Hypertension Unit, Università Vita Salute San Raffaele, Via Olgettina 60, 20132 Milan, Italy

$\begin{array}{ll}\text { FST } & \text { Furosemide stress test } \\ \text { IGFBP7 } & \text { Insulin-like growth factor-binding protein 7 } \\ \text { IL-18 } & \text { Interleukin-18 } \\ \text { KIM-1 } & \text { Kidney injury molecule-1 } \\ \text { NAG } & N \text {-Acetyl- } \beta \text {-D-glucosaminidase } \\ \text { NGAL } & \text { Neutrophil gelatinase-associated lipocalin } \\ \text { OR } & \text { Odds ratio } \\ \text { ROC } & \text { Receiver operating characteristic curve } \\ \text { RRT } & \text { Renal replacement therapy } \\ \text { sCr } & \text { Serum creatinine } \\ \text { TIMP2 } & \text { Tissue inhibitor of metalloproteinases 2 }\end{array}$

\section{Introduction}

Acute kidney injury (AKI) is an important health problem. Patients who develop AKI have markedly increased in-hospital mortality and, even if they do survive the acute phase, they still have an increased likelihood of morbidity and mortality over the long term [1-3]. Current treatments focus on avoiding the potential injury due to nephrotoxic drugs or intravenous contrast agents, and on providing supportive care [3]. Theoretically speaking, more specific therapies have been identified in animal models, but their efficacy has not been proven in subsequent human clinical trials; this is because AKI is difficult to identify before loss of organ function sets in, by which time the damage may be irreversible [4]. Therefore, there is growing expectation about the development of biomarkers that can identify AKI in its earliest stage, when interventions could be more successful. In particular, of great interest is the possibility of individual risk stratification for AKI, in order to avoid any unnecessary kidney stress and, if appropriate, to start a preventive treatment [4]. 
For all these reasons, over the last decade there has been considerable progress made in the discovery and development of new tools, predictive models and biomarkers of AKI; several of them have now been evaluated in different clinical settings [5-7]. Although there is a growing literature on the performance of various biomarkers in clinical studies, information is limited on how these biomarkers could be used by clinicians to manage patients with AKI [5].

The purpose of this narrative paper is to review the current state of the art in prediction and early detection of AKI. This shall be done by describing the most important and promising tools, biomarkers and potential innovations in this field. We will also focus on their real and potential applications in everyday clinical practice.

\section{New biomarkers of AKI}

Accessible markers of AKI can be components of serum or urine. Hopefully, one or more of these biomarkers, either alone or in combination, will prove to be useful in facilitating early diagnosis, guiding targeted interventions and monitoring the disease progression and resolution [8]. The most important and promising biomarkers are summarized in Table 1.

\section{Neutrophil gelatinase-associated lipocalin}

Human neutrophil gelatinase-associated lipocalin (NGAL) is a $25-\mathrm{kDa}$ protein initially identified bound to gelatinase in specific granules of the neutrophil. NGAL is synthesized during a narrow window of granulocyte maturation in the bone marrow [9], but may also be induced in epithelial cells in the setting of inflammation or malignancy [10]. NGAL should be considered as a marker of tubular damage [11].

NGAL was identified as being one of the seven genes whose expression was upregulated more than tenfold within the first few hours after ischemic renal injury in a mouse model [12]. Although it was shown that exogenous administration of NGAL protects against ischemic kidney injury in mice [13], lipocalin-2 knockout mice do not exhibit increased sensitivity to bilateral renal ischemia/ reperfusion injury [14]. NGAL is upregulated and can be detected in the kidney [15] and urine of mice $3 \mathrm{~h}$ after cisplatin $(20 \mathrm{mg} / \mathrm{kg})$ administration and it has been proposed as an early biomarker for diagnosing AKI [16]. A prospective study of pediatric patients undergoing cardiopulmonary bypass (CPB) for cardiac corrective surgery found urinary NGAL to be a powerful early marker of AKI, preceding any increase in serum creatinine ( $\mathrm{SCr}$ ) by $1-3$ days [17]. A similar study of adult patients showed urinary NGAL levels at 1,3 , and $18 \mathrm{~h}$ after cardiac surgery to be significantly higher in patients who went on to develop clinically

Table 1 Overview of the most recent and promising biomarkers for early detection of AKI

\begin{tabular}{|c|c|c|c|c|c|}
\hline Biomarker & Settings studied & Source & Measured from & Used for & $\begin{array}{l}\text { Diagnostic } \\
\text { accuracy } \\
\text { (ROC) }\end{array}$ \\
\hline NGAL & $\begin{array}{l}\text { Cardiac surgery, ER, hos- } \\
\text { pitalized patients, kidney } \\
\text { Tx, sepsis, critically-ill } \\
\text { patients }\end{array}$ & $\begin{array}{l}\text { Leukocytes, loop of henle } \\
\text { and collecting ducts }\end{array}$ & $\begin{array}{l}\text { Serum plasma } \\
\text { Urine }\end{array}$ & $\begin{array}{l}\text { Detection of established AKI, } \\
\text { early diagnosis, prognosis }\end{array}$ & $0.53-0.96$ \\
\hline Cystatin-C & $\begin{array}{l}\text { Hospitalized patients, } \\
\text { cardiac surgery }\end{array}$ & Nucleated cells & $\begin{array}{l}\text { Serum plasma } \\
\text { Urine }\end{array}$ & $\begin{array}{c}\text { Detection of established AKI, } \\
\text { early diagnosis, prognosis }\end{array}$ & $0.79-0.89$ \\
\hline KIM-1 & $\begin{array}{l}\text { Hospitalized patients, } \\
\text { cardiac surgery }\end{array}$ & Proximal tubular cells & Urine & $\begin{array}{l}\text { Increased risk of AKI, estab- } \\
\text { lished AKI, prognosis }\end{array}$ & $0.61-0.78$ \\
\hline IL-18 & $\begin{array}{l}\text { Cardiac surgery, ICU, hos- } \\
\text { pitalized patients, Tx }\end{array}$ & $\begin{array}{l}\text { Monocytes, dendritic cells, } \\
\text { macrophages }\end{array}$ & Urine & $\begin{array}{l}\text { Detection of established AKI, } \\
\text { early diagnosis, prognosis }\end{array}$ & $0.70-0.95$ \\
\hline FABPs & $\begin{array}{l}\text { Contrast nephropathy, } \\
\text { Sepsis, cardiac surgery, } \\
\text { ischemic/reperfusion } \\
\text { injury }\end{array}$ & $\begin{array}{l}\text { Hepatocytes, proximal } \\
\text { tubular cells }\end{array}$ & Urine & $\begin{array}{l}\text { Detection of established AKI, } \\
\text { progression to CKD }\end{array}$ & $0.84-0.96$ \\
\hline TIMP-2 and IGFBP7 & $\begin{array}{l}\text { Major surgery, sepsis, } \\
\text { shock, trauma }\end{array}$ & Tubular epithelial cells & Urine & $\begin{array}{l}\text { Detection of established AKI, } \\
\text { prognosis }\end{array}$ & $0.76-0.85$ \\
\hline EO & Cardiac surgery & Adrenal cells & Plasma & $\begin{array}{l}\text { Identification of patients with } \\
\text { increased risk of AKI }\end{array}$ & $0.73-0.80$ \\
\hline
\end{tabular}

$E O$ endogenous ouabain, $E R$ emergency room, $F A B P S$ fatty acid-binding proteins, $I C U$ intensive care unit, $I G F B P 7$ insulin-like growth factorbinding protein 7, IL-18 interleukin-18, KIM-1 kidney injury molecule-1, $N G A L$ neutrophil gelatinase-associated lipocalin, $R O C$ receiver operating characteristic curve, TIMP2 tissue inhibitor of metalloproteinases 2, Tx transplantation 
significant AKI [18]. Elevated NGAL levels have also been reported in heart failure, coronary heart disease, and stroke; some studies have shown NGAL to be an independent predictor of major adverse cardiovascular events and mortality [19-21].

NGAL has been one of the most widely studied biomarkers in AKI [22], in particular in the cardio-surgical field $[23,24]$. NGAL has been tested in multiple studies that have included a total of more than 4000 patients at risk for AKI due to sepsis, cardiac surgery, exposure to contrast media, or after renal transplantation. In these studies, the average sensitivity and specificity of NGAL ranged from 70 to $80 \%$, upon different king of ARF triggering mechanism (sepsis vs. cardiac surgery). The diagnostic accuracy (receiver operating characteristics, ROC) was among 0.53 and 0.96 [25-28]. Moreover, in a recent extensive metaanalysis of data from 19 studies including $>2500$ patients, serum and urine NGAL levels were found not only to be diagnostic of AKI, but also able to predict clinical outcomes such as need for dialysis and mortality [21].

NGAL shows the potential to be a simple and powerful biomarker able to provide an early (within a few hours) AKI diagnosis [17], and capable of differentiating between prerenal kidney disease and acute tubular necrosis (ATN) [29]. NGAL tests are available for clinical use in Europe and will eventually be available in North America too, although it is not clear which test (urine vs. plasma sample) provides the best diagnostic performance for AKI. Some authors have suggested that a combination of the two tests might be the best option [25].

\section{Cystatin-C}

Cystatin-C (Cys-C) is a 13-kDa protein that was initially known as interalia $\gamma$-trace, post- $\gamma$-globulin, and gammaCSF and is believed to be one of the most important extracellular inhibitors of cysteine proteases. Cys-C is freely filtered by the glomerulus, reabsorbed and catabolized, but not secreted, by the tubules. Over the past decade, serum Cys- $\mathrm{C}$ has been extensively studied and found to be a sensitive serum marker of the glomerular filtration rate (GFR) and a stronger predictor than $\mathrm{SCr}$ of risk of death and cardiovascular events in older patients [30, 31]. The only rodent study in which Cys-C was measured was in the rat model of end-stage renal disease (ESRD) in which sequential bilateral nephrectomy was carried out 7 days apart. The kinetics of changes in serum Cys-C and creatinine concentrations mimicked the clinical condition [32]. Urinary Cys-C levels have been found to be elevated in individuals with known tubular dysfunction [33, 34]. In addition, HergetRosenthal et al. reported that elevated urinary Cys-C levels were highly predictive of poor outcome (i.e. need for renal replacement theory, RRT) in a heterogeneous group of patients with initially nonoliguric AKI [35]. In one prospective study, Cys-C was measured in both the plasma and urine of patients undergoing cardiac surgery. Within the first $6 \mathrm{~h}$ urinary values of Cys-C rose predicting AKI, but no change was observed in plasma levels, suggesting that the urinary test might be superior to the plasma assay for the early detection of AKI [36].

When compared with ( $\mathrm{SCr}$ ), Cys-C seems to be less affected by age, gender, and body weight. Serum levels of Cys-C are a more precise indicator of kidney function than SCr levels $[37,38]$ but seem to be influenced by large doses of corticosteroids, hyperthyroidism, inflammation, hyperbilirubinemia and hypertriglyceridemia [39, 40]. Currently, it is unclear if the value of Cys-C is generalizable to all forms of AKI or is specific to particular populations [41-43].

\section{Kidney injury molecule-1}

Kidney injury molecule-1 (KIM-1) is a type I cell membrane glycoprotein containing a unique six-cysteine immunoglobulin-like domain and a mucin domain in its extracellular region. KIM-1 was initially identified using representational difference analysis on kidneys following ischemia/reperfusion injury: KIM-1 mRNA levels increased more than any other known gene after kidney injury [44]. In preclinical and clinical studies using several mechanistically different models of kidney injury, urinary Kim-1 has been used as an early diagnostic indicator of kidney injury $[45,46]$. Several reports have shown that KIM-1 appears to be a very sensitive indicator of AKI in noncardiac surgical patient populations [47], and after cardiac surgery [48]. Han et al. demonstrated marked expression of KIM-1 in kidney biopsy specimens from 6 patients with acute tubular necrosis, and found elevated urinary levels of KIM-1 within $12 \mathrm{~h}$ after an initial ischemic renal insult, prior to the appearance of casts in the urine. Moreover, this work showed that increased KIM-1 level was associated with a greater than 12 -fold (odds ratio, OR 12.4, 95\% confidence interval, CI 1.2-119) risk for the presence of ATN [45]. Liangos et al. studied urinary KIM- 1 and $N$-acetyl- $\beta$ D-glucosaminidase (NAG) in 201 patients with established AKI and found that elevated levels of urinary KIM-1 and NAG were significantly associated with the clinical composite endpoint of death or dialysis requirement, even after adjustment for disease severity or comorbidity [49].

KIM-1 seems to be very useful in differentiating ATN from other forms of AKI. Furthermore, Koyner et al. also described a predictive preoperative power of KIM-1 in relation to the development of stage 1 and stage $3 \mathrm{AKI}$; this is probably due to the presence of subclinical proximal tubular injury reflected in increased KIM-1 levels [50]. 


\section{Interleukin-18}

Interleukin-18 (IL-18) is a cytokine that has been identified as an interferon- $\gamma$ (IFN- $\gamma$ )-inducing factor in livers of mice treated with Propionibacterium acnes and lipopolysaccharide [51]. The precursor form of IL-18 (24 kDa) is enzymatically cleaved by IL- $1 \beta$-converting enzyme to produce mature $18-\mathrm{kDa}$ IL-18 protein [52]. Renal IL-18 mRNA levels have been shown to be significantly upregulated following ischemia-reperfusion injury, inflammatory/autoimmune nephritis, and cisplatin-induced nephrotoxicity [53].

Urinary IL-18 levels are elevated in patients with AKI and delayed graft function compared to normal subjects and patients with prerenal azotemia, chronic renal insufficiency, and nephrotic syndrome [54]. IL-18 has been shown to be more elevated in patients with established acute tubular necrosis AKI than in those with prerenal azotemia, urinary tract infection, or chronic kidney disease (CKD) $[55,56]$. In particular, in a study of critically-ill adult patients with acute respiratory distress syndrome (ARDS), increased urinary IL-18 was found to be an early marker of AKI, preceding changes in serum creatinine by 1-2 days, and was also an independent predictor of death [56].

\section{Fatty acid-binding protein}

Fatty acid-binding proteins (FABPs) are small $(15 \mathrm{kDa})$ cytoplasmic proteins abundantly expressed in all tissues with active fatty acid metabolism [57]. Two types of FABP have been identified in the human kidney: liver-type FABP (L-FABP) in the proximal tubule and heart-type FABP (H-FABP) in the distal tubule [58, 59]. Free fatty acids (FFAs) in proximal tubules are bound to cytoplasmic FABPs and transported to mitochondria or peroxisomes, where they are metabolized by $\beta$-oxidation [60]. Urinary L-FABP has been identified in preclinical and clinical models and has been found to be a potential biomarker in a number of pathologic conditions, including CKD, diabetic nephropathy, IgA nephropathy, and contrast nephropathy. Using human L-FABP (hL-FABP) transgenic mice, it has been demonstrated that protein-overload nephropathy and unilateral ureteral obstruction, two models of renal interstitial injury, are associated with increased expression and urinary excretion of L-FABP $[61,62]$. In a clinical study, elevated urinary levels of L-FABP were found to be an independent predictor of AKI (elevation time within 4-24 h) [63]. In both injured models, a less severe tubulointerstitial damage was observed in the transgenic mice when compared with wild-type mice, supporting the notion that L-FABP plays a protective role in the setting of increased renal tubular stress [64]. L-FABP has also been advocated as a potential biomarker for monitoring progression of CKD. Kamijo et al. found increasing L-FABP levels with deterioration of renal function in patients with nondiabetic CKD [62]. In addition, Nakamura et al. have reported that urinary L-FABP may serve as a noninvasive biomarker to discriminate between IgA nephropathy and thin basement membrane disease [65] as well as a potential predictive marker for contrast-induced nephropathy [66]. Although L-FAPB appears to be an attractive candidate biomarker for a number of renal diseases, additional studies are needed to determine the utility of L-FABP in AKI, especially in the setting of ischemia/reperfusion injury, nephrotoxin exposure, and sepsis.

\section{TIMP-2 and IGFBP7}

Tissue inhibitor of metalloproteinases 2 (TIMP2) and insulin-like growth factor-binding protein 7 (IGFBP7) are markers of cellular stress in the early phase of tubular cell injury caused by a wide variety of insults (inflammation, ischemia, oxidative stress, drugs, and toxins) [67-70]. Therefore, both markers are involved in the process of G1 cell-cycle arrest that prevents cells from dividing in the case of damage to the DNA until such damage can be repaired [71]. Importantly, both biomarkers appear as "alarm" proteins for other nearby cells in a paracrine fashion $[72,73]$. Two multicenter observational studies were performed in critically-ill patients at risk for AKI [74]. The top two markers from the discovery phase were validated in a second study (Sapphire) and compared to a number of previously described biomarkers. In the discovery phase, 522 adults were enrolled in three distinct cohorts including patients with sepsis, shock, major surgery, and trauma and over 300 markers were examined. In the Sapphire validation study, 744 adult subjects with critical illness and without evidence of AKI (at enrolment) were enrolled; the final analysis cohort was a heterogeneous sample of 728 critically-ill patients (14\% with moderate to severe AKI). IGFBP7 and TIMP-2, used together, demonstrated an area under the curve (AUC) for AKI of 0.80 (0.76 and 0.79 alone). Furthermore, combined used of IGFBP7 and TIMP-2 significantly improved risk stratification when added to a 9-variable clinical model.

\section{Endogenous ouabain}

Endogenous ouabain (EO) is a neuroendocrine hormone synthesized in the adrenal cortex [75-77]. EO modulates the activity of $\mathrm{Na}$, K-ATPase and induces signal transduction via sodium-calcium exchange and the Src-dependent pathway [78]. The hypertensive effect of EO is well established in both animal and human models [79-81], as well as its association with organ damage [82, 83]. Furthermore, a rat model of ouabain-induced hypertension exhibited reduced creatinine clearance, proteinuria, and impaired 
podocyte nephrin expression; thus, elevated EO per se may be a direct cause of podocyte damage. Ouabain-infused rats exhibited a significant reduction of creatinine clearance $(-18 \%, \mathrm{p}<0.02)$ and an increase in urinary protein excretion $(+54 \%, \mathrm{p}<0.05)$ compared to controls [84]. The mechanism of the EO effect is likely mediated by changes in cell $\mathrm{Ca}^{+}$(activation of the $\mathrm{Ca}^{++}$-dependent protease calpain [85] with an increase in nephrin protein cleavage [86]) or, via NFkB (active activation of the transcriptional regulator Snail with reduction in nephrin expression [87]).

Recently, a significant association has been reported of preoperative EO levels with adverse renal outcomes in cardiac surgery patients and with mortality in critically-ill patients. In one study [84], elevated preoperative EO levels were associated with a higher incidence of postoperative AKI (20.3 vs. $2.8 \%, \mathrm{p}<0.001)$ and ICU stay $(2.4 \pm 0.59$ vs. $1.4 \pm 0.38$ days, $\mathrm{p}=0.014)$; in a second study [88], the preoperative EO value was added to a different clinical AKI predictive model and resulted in a significant improvement of risk prediction power (AUC of AKI from 0.79 to 0.84 ; $\mathrm{p}<0.0001)$. Finally, post-operative EO levels were also associated with a higher mortality rate after cardiac surgery [89].

\section{Other new potential biomarkers}

Recently, some new potential biomarkers have been proposed for early determination of AKI in specific conditions. Clusterin [8, 90], osteopontin [91], intestinal trefoil factor (TFF3) [92], glutathione-S-transferase (GST) [93, 94] and pyruvate kinase M2 [95] were associated with the development of drug-induced nephrotoxicity in an in vitro study and animal models focusing on potential new mechanisms of development of renal damage [95]. However, further investigations are needed to confirm these relationships and the potential benefits of these new molecules.

\section{Transition from AKI to CKD}

A potential association has been described between some of the new early biomarkers of AKI and the presence of chronic subclinical kidney damage. In this way, these biomarkers should also be considered markers of progression from AKI to CKD with a prognostic value.

\section{$N G A L$}

In a cross-sectional study of 80 non-diabetic patients with CKD stages 2-4, serum NGAL was found to be elevated in those with the most advanced CKD [96]. Moreover, urinary and serum NGAL levels have been noted to be elevated in a wide range of kidney diseases, including diabetic nephropathy, autosomal polycystic kidney disease and $\operatorname{IgA}$ nephropathy [97, 98]. NGAL was also identified in an animal model as an active player in kidney disease progression [99].

\section{KIM-1}

In a retrospective study of patients with non-diabetic proteinuric kidney disease, KIM-1 levels in urine were found to be elevated, but subsequently decreased when patients received treatment with angiotensin-converting enzyme inhibitors or a low-sodium diet [100]. In a recent study of a cohort of patients with type 1 diabetes and proteinuria, serum KIM-1 level at baseline strongly predicted the rate of estimated GFR loss and risk of ESRD during 5-15 years of follow-up [101]. Moreover, in an animal model KIM-1 showed a potential direct role in CKD progression by promoting kidney fibrosis, interstitial kidney inflammation and progressive renal failure with anemia, proteinuria, hypertension, and cardiac hypertrophy [102].

\section{$L-F A B P$}

In two different studies (on diabetic and non-diabetic patients), urinary L-FABP was found to be more sensitive than proteinuria in predicting the progression of CKD [103, 104].

Cys-C is considered a "functional biomarker" of AKI because it is freely filtered and reabsorbed by the proximal tubule and this process is inhibited in the presence of kidney damage [43]. It has been suggested that Cys-C might better predict the risk of developing CKD, highlighting a state of 'preclinical' kidney dysfunction rather than identifying the early phase of AKI [105]. Moreover, other data suggest that Cys-C is modified by age, sex, muscle mass, obesity, smoking status, thyroid function, inflammation, and malignancy. These factors suggest the need for agespecific and sex-specific reference standards [106].

\section{Ongoing problems with novel biomarkers}

Although all these new molecules are promising candidate biomarkers for AKI, they are still rarely used in everyday clinical practice. Even if the primary results are really encouraging, the use of Cys-C, NGAL or other alternative makers of early AKI is still an area of ongoing research [107]. Indeed, recently some authors have shown that there are a couple of "blind spots" in the use of these new markers and, sometimes, the real meaning of the increased levels of NGAL, KIM-1 or other biomarkers is not completely understood [108, 109]. Some authors reported the inability of these new biomarkers to predict AKI with sufficient clinical pertinence to justify the cost of these analyses in routine practice $[109,110]$. And some of the biomarkers have 
still not been evaluated with enough data in very specific populations (infant and elderly) [43, 111].

Furthermore, the assays for detection are not standardized and it is still under discussion whether is better to use urine or plasmatic values. Indeed, Mårtensson et al. proposed that the plasma NGAL level is a closer reflection of systemic inflammation than of the extent of renal injury inflicted [112]. Finally, the presence of these new markers in the urine leads to another problem: the real availability and reliability of these tests in critically-ill patients, where urine output is reduced (or totally absent) and usually forced by drugs. In conclusion, the data in our possession are still inconsistent and additional studies are needed to focus on the cost-effectiveness of earlier detection of AKI with these new compounds compared to creatinine, and to determine whether these biomarkers have complementary value. This is, at least in part, due to the heterogeneity of AKI subtypes, that is a great limit for large population studies in human subjects.

\section{Sepsis-induced AKI}

Sepsis represents the one of the main causes of AKI in developed countries [113, 114]. It is estimated that more than $20 \%$ of septic patients may show some degree of AKI, and the mortality rate of this subgroup will increase up to $35 \%[115,116]$. Although sepsis is one of the most common causes of AKI, the framework for the identification and management of sepsis-induced (or sepsis-associated) acute kidney injury (SI-AKI) has not been well established $[114,117]$. Both the severity of the kidney injury and the clinical implications (morbidity and mortality rate) worsen with delayed recognition of the injury itself. Moreover, because no singular effective therapy has been uncovered, early initiation of supportive care is the milestone of therapy (sepsis-associated acute kidney injury). It is easy to understand why early detection is of critical importance in SI-AKI. In fact, traditional urinary indices and biochemistry (such as $\mathrm{SCr}, \mathrm{FeNa}$ and $\mathrm{FeU}$, urine sodium, etc.) are totally inadequate to delineate subtypes and severity of AKI during sepsis [118-120].

Novel AKI biomarkers already have shown an ability to identify SA-AKI before SCr levels. Plasma and urine NGAL levels were significantly higher in 83 patients with SA-AKI compared to patients with nonseptic AKI [121]. In 150 critically-ill adult patients, urinary NGAL showed significant discrimination for AKI in patients with sepsis $(A U C=0.80)$ [122] but serum NGAL levels alone showed only a marginal predictive capacity for AKI in children with sepsis (AUC, 0.68). Also KIM-1 was reported to be effective in early (within $3 \mathrm{~h}$ of admission) identification of acute kidney dysfunction in a subset of 150 septic patients [123]. In a large multicenter study of critically-ill adults
[74], TIMP-2 and IGFB7 showed the best predictive power $(\mathrm{AUC}=0.82)$ in a subset of patients with sepsis. Its AKI prediction power was superior to other novel biomarkers such as NGAL, IL-18, L-FABP and KIM-1.

Finally, some studies have shown an association between SI-AKI and some acute phase proteins or kidney function protein. E-selectin (inflammatory and endothelial activation protein) was associated with AKI in patients after sepsis [124]; microalbuminuria was also able to predict subsequent development of AKI (AUC $=0.86$ ) in an observational cohort study on septic patients [125].

Unfortunately, several studies reported that plasma levels of some molecules (e.g. NGAL and Cys-C) are deeply influenced by the inflammatory state [106, 122, 126, 127]; this could represent a potential limit for the clinical use of these new biomarkers in the presence of systemic inflammation. Simultaneous comparison of plasma and urine levels of biomarkers is mandatory and should represent an effective way to overcome this problem.

\section{Tools for AKI predicion and severity diagnosis}

Recently several tools have been proposed to determine the severity of kidney damage and the long-term patient prognosis after kidney injury has been established [128]. Between these options, the most valuable and promising in terms of cost-effectiveness seem to be the furosemide stress test (FST), the renal functional reserve (RFR) examination and predictive models.

\section{Furosemide stress test}

Koyner et al. [128] recently demonstrated that the 2-h urine output after a standardized high-dose furosemide stress test (FST), $1 \mathrm{mg} / \mathrm{kg}$ of furosemide in naive patients or $1.5 \mathrm{mg} /$ $\mathrm{kg}$ in those with prior exposure, in clinically euvolemic patients with early AKI has the predictive capacity to identify those with severe and progressive AKI [129]. The area under the ROC curve (AUC) for 2-h urine output after FST was 0.87 for severe AKI (AKIN stage-3) in a subset of 77 patients $(p=0.001)$. The ideal cutoff for predicting progressive AKI during these first $2 \mathrm{~h}$ was a urine volume $<200 \mathrm{ml}$ (or $<100 \mathrm{ml} / \mathrm{h}$ ) with a sensitivity of $87.1 \%$ and a specificity of $84.1 \%$ [129]. These data demonstrate that urine output in the first $2 \mathrm{~h}$ after FST outperforms several biomarkers of AKI for the prediction of AKI progression and future need for RRT. Specifically, FST was significantly better than our complete panel of urinary biomarkers at predicting progression to AKIN stage 3. The addition of biomarkers to FST results did not provide any additional benefit. Similarly, FST outperformed all other biomarkers in predicting the end point of receipt of RRT and inpatient death. 


\section{Renal functional reserve test}

The concept of renal functional reserve (RFR) was introduced in the $80 \mathrm{~s}$ [130]. The renal functional reserve was defined as the ability of the kidney to increase renal plasma flow (RPF) and GFR after a stimulus such as a protein load [131, 132]. GFR is not a fixed function and it may increase in healthy subjects in response to different stimuli (both physiological and pathological); the absence of RFR defines a state of hyper-filtration which seems to be a negative factor for the progression of renal failure [133]. This capacity to increase the level of function depends on an intact nephron mass and describes RFR. In this way, subjects with a reduction in RFR were considered 'sub-clinical AKI' with an increased susceptibility of the kidney even in the presence of mild exposure [133]. There is no single validated method/test available to determine RFR in an easy, accurate way and which could be used in clinical practice, although in the past multiple attempts have been made [134-136]. Recently, Sharma and Ronco described a standard protocol for a 'renal stress test' (RST) to evaluate RFR using weight-adjusted oral protein loads $(1 \mathrm{~g} / \mathrm{kg})$ in healthy subjects [137]. This test, performed in 18 healthy volunteers, seems to be very easy and accurate with no clinical risks for the patients. Moreover, Pekkafal and Kara proposed the incorporation of a Doppler resistive index (RI) and pulsatility index (PI) into the assessment of RFR [138]. The RFR assessment should be of particular utility in specific clinical situations (such as determining the status of the kidneys in potential living kidney donors; preparatory evaluation/counseling, etc.) [133].

\section{Models predicting AKI}

Considering the ongoing issues regarding early AKI detection, it is becoming strategically important to identify subjects with an increased risk of acute renal damage after a therapeutic procedure. This is dramatically true, for example, in post-surgical AKI. More so, neither the new markers of early AKI nor, least of all, the "classic" SCr or bloodurea-nitrogen (BUN) levels are able to identify susceptible patients. All these molecules start to increase in blood and urine when the kidney damage already exists; but it is reported that poor outcomes can be observed just with an increased risk of AKI, even before the kidney damage occurs (see Fig. 1). An accurate, validated prediction model for AKI after cardiac surgery could help in clinical decision making, patient counseling, informed decision making, resource utilization, and preoperative medical optimization [139]. For these reasons, in the last 15 years many new models predicting AKI have been proposed [88, 140-146]. Based simply on good clinical "observation", these models can predict post-operative AKI with a fairly good power, usually expressed by an AUC between 0.76 and 0.84 . Recently, two meta-analyses [7, 147] compared the most important predictive models, showing the strengths and weaknesses of each. The main features of all models are summarized in Table 2.

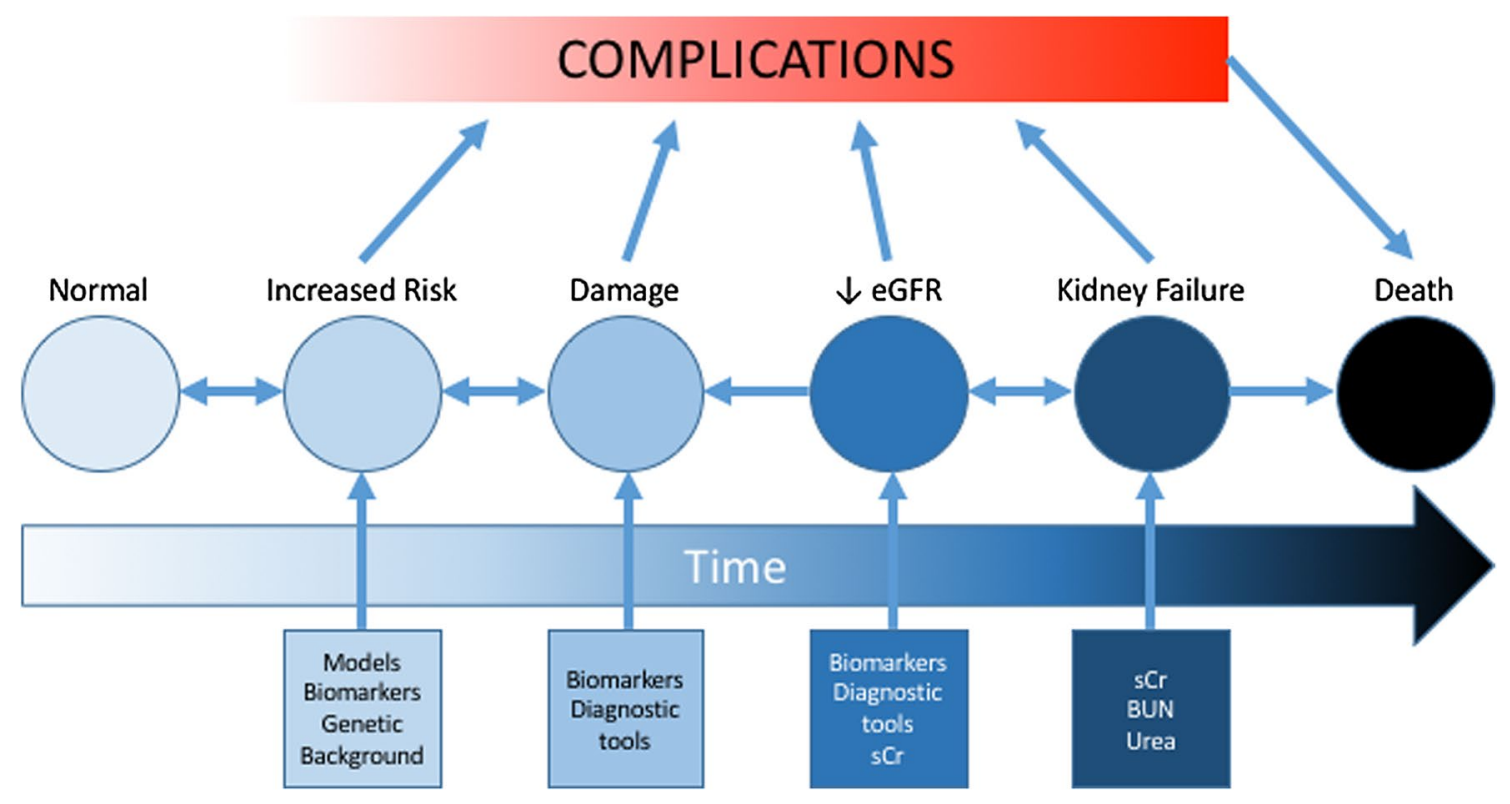

Fig. 1 AKI development: distribution of various diagnostic tools across the timeline of the development of acute kidney injury. Clinical predictive models, identification of a favorable genetic background and biomarkers of individual susceptibility (like EO or KIM-
1) could be used to identify patients with an increased risk of renal complication. All the other new biomarkers and useful diagnostic tools might be used to determine diagnosis of AKI as early as possible after the damage has occurred 
Table 2 Overview of the most important clinical predictive models of post-surgical AKI

\begin{tabular}{|c|c|c|c|c|c|c|c|c|}
\hline Model name & CICSS & $\begin{array}{l}\text { Cleveland } \\
\text { clinic }\end{array}$ & STS & SRI & MCSPI & AKICS & NNECDSG & CLIN-RISK \\
\hline First author & Chertow & Thakar & Mehta & Wijeysundera & Aronson & Palomba & Brown & Simonini \\
\hline Year of study & 1987-1994 & 1993-2002 & 2002-2004 & 1999-2004 & 1996-2000 & 2003-2005 & 2001-2005 & 2009-2012 \\
\hline $\begin{array}{c}\text { Number of } \\
\text { patients }\end{array}$ & 42,733 & 15,838 & 449,525 & 10,751 & 2381 & 603 & 8363 & 802 \\
\hline Outcome $(\%)$ & AKI-D (1.1) & AKI-D (1.7) & AKI-D (1.4) & AKI-D (1.3) & AKI-ND (4.8) & AKI-ND (11) & AKI-ND (3) & AKI-ND (9.9) \\
\hline $\mathrm{ROC}$ & 0.76 & 0.81 & 0.84 & 0.81 & 0.84 & 0.84 & 0.72 & 0.79 \\
\hline $\begin{array}{l}\text { Validation } \\
\text { (ROC) }\end{array}$ & $\begin{array}{c}\text { Yes }(0.71- \\
0.78)\end{array}$ & $\begin{array}{c}\text { Yes }(0.66- \\
0.86)\end{array}$ & $\begin{array}{c}\text { Yes }(0.75- \\
0.81)\end{array}$ & $\begin{array}{c}\text { Yes }(0.73- \\
0.79)\end{array}$ & $\mathrm{Yes}^{\#}(0.80)$ & $\mathrm{Yes}^{\#}(0.85)$ & Yes $(0.76)$ & No \\
\hline $\begin{array}{r}\text { Number of } \\
\text { variables }\end{array}$ & 7 & 13 & 10 & 8 & 8 & 8 & 11 & 8 \\
\hline Demographics & & $\mathrm{X}$ & $\mathrm{X}$ & & $\mathrm{X}$ & $\mathrm{X}$ & $\mathrm{X}$ & $\mathrm{X}$ \\
\hline Clinical & $\mathrm{X}$ & $X$ & $X$ & $\mathrm{X}$ & $X$ & $X$ & $X$ & $X$ \\
\hline Operation type & $X$ & $X$ & $X$ & $X$ & & $X$ & & $X$ \\
\hline Intraoperative & & & & & $\mathrm{X}$ & $X$ & & \\
\hline Postoperative & & & & & & $X$ & & \\
\hline
\end{tabular}

$A K I-D$ AKI requiring dialysis, AKI-ND AKI not requiring dialysis, AKICS Acute Kidney Injury After Cardiac Surgery Score, CICSS Continuous Improvement in Cardiac Surgery Study, CLIN-RISK Clinical Risk Score for AKI, MCSPI Multicenter Study of Perioperative Ischemia Score, NNECDSG Northern New England Cardiovascular Disease Study Group Score, SRI simplified renal index, STS Society of Thoracic Surgeons Bedside Risk Tool

\#Only internal validation

The most robust and externally validated models are for AKI requiring dialysis. However, dialysis events are rare $(1-2 \%)$ and frequently occur several days after the operation, limiting the benefit of application of these scoring systems [7]. More studies are needed to develop and validate scores to predict milder AKI not requiring dialysis, which is very common and contributes to several in-hospital outcomes. Unfortunately, the studies on models with a more sensitive definition of AKI suffer from different definitions of AKI, small cohorts and the lack of external validation. Moreover, in most proposed models the use of intraoperative variables greatly reduces their utility in clinical practice. Indeed, what we would get is a real prediction "a priori" of AKI risk, not just a score for post-event outcomes.

Despite all these limitations, the use of clinical prediction models for AKI is currently the only validated strategy available to identify patients with a particularly high risk. Recently, several studies [88] have shown that combining the clinical variables and the new biomarkers could significantly increase the predictive power for the development of AKI compared to the clinical models alone. These results appear more interesting when biomarkers of individual susceptibility are chosen because in this way the pre-operative prediction power of the models is preserved.

\section{Renal angina}

A new concept — renal angina-was introduced in 2010 by Goldstein and Chawla [117, 148]. The term 'angina' was used in the context of AKI to identify the development of clinical or subclinical renal injury. Renal angina (RA) is not associated to a physical symptomatology (like pain) but is rather a conceptual framework to identify evolving AKI based on the presence of oliguria (for $1 \mathrm{~h}$ ), any increase in $\mathrm{SCr}(>0.1 \mathrm{mg} / \mathrm{dl})$, and fluid overload [148-150]. The RA concept has been assessed in one large cohort of criticallyill adult patients with good results: it demonstrated a high sensitivity (92\%) associated with the development of AKI, and an extremely high (99\%) negative predictive value [151]. Moreover, for a better detection of renal angina, a bedside assessment tool called the Renal Angina Index (RAI) has been developed in the pediatric population. The performance of the RAI in different pediatric cohorts was remarkably consistent, with a risk prediction AUC of $0.74-0.81$ [152]. In conclusion, RA probability assessment in AKI appears to have good performance metrics both in children and adults; future research will need to adjust and recalibrate the RA concept, especially in combination with other AKI biomarkers [153]. 


\section{Emerging concepts in AKI: genetic susceptibility and new "OMICS" technologies}

It is well known in clinical practice that two patients with identical backgrounds and clinical risk factors can react differently to the same insult. Therefore, models using traditional risk factors remain inadequate [142, 154-156]. Furthermore, we are still unable to predict who is going to go on to chronic dialysis and who is going to recover. However, some of these risk factors may be elucidated by two emerging fields: perioperative genomics and new biomarkers derived from the new 'OMICS' technologies.

\section{Genetic susceptibility}

In AKI the role of genetic variation as a determinant of both risk and outcome is not well defined [157]. Recently an individual genetic AKI susceptibility has also been proposed [158-160]. Traditional methods of identifying genetic associations are based on multigenerational studies but, by definition, this type of study is not feasible in the field of perioperative medicine. Using association studies, a large number of genetic polymorphisms have been identified that are able to predict different and variable kidney responses in the face of the same kind of injury [157]. In summary, the majority of these high-risk genetic variants are associated to a proinflammatory state, the response to oxidative stress, or alteration of renal vascular response [161]. It is also probable that a patient's DNA sequence variants have more effect on host repair and regeneration biology than the risk of AKI per se [157].

\section{Proinflammatory genes}

Usually in postoperative cardiac surgery, the patient's inflammatory mediators are elevated because CPB, ischemia-reperfusion injury and endotoxemia from general hypoperfusion represent a significant systemic inflammatory trigger $[162,163]$. As a consequence, it was supposed that patients who are genetically predisposed to an exaggerated immune response may also be more susceptible to postoperative AKI. Specific polymorphism of IL-6 and tumor necrosis factor (TNF)- $\alpha$ genes were reported to be associated to AKI predisposition (hazard ratio, HR, for TNF- $\alpha 2.47, p=0.04)[155,159,164]$.

\section{Renal vascular tone modulators}

Polymorphisms of modulators of renal vascular tone have also been proposed as mediators of increased renal risk. These genes include angiotensin-converting enzyme insertion/deletion (ACE I/D), angiotensinogen, angiotensin receptor 1, and endothelial NO synthase [157]. Only a single positive study [165] reported an increased risk in association with ACE D allele (odds ratio, OR, 2.37, $\mathrm{p}=0.021$ ).

\section{Apolipoprotein E}

Polymorphism $\varepsilon 4$ apolipoprotein E (APOE), an important regulator of lipoprotein metabolism and immunomodulation, has been associated with a postoperative rise in creatinine in several studies $[165,166]$ in patients after coronary artery bypass graft (CABG). This finding has not been confirmed in a more consistent multiple studies.

\section{Other genes}

Oxidative stress genes (like NADPH) and haptoglobin 2-2 polymorphism have been studied as contributors to postoperative risk [167, 168]. Preliminary results showed an association between these gene polymorphisms and AKI onset, dialysis and mortality (OR, respectively, 2.11 and $5.4, \mathrm{p}<0.05)$.

\section{Ongoing problems with perioperative genomics}

Although several polymorphisms have been investigated, most studies focused on a select number of individual genes in small homogenous sample populations. Overall, the results have been variable and often inconsistent across studies [157]. The lack of robust and reproducible associations is not surprising given the complex, multifactorial nature of perioperative renal injury. In addition, we have a rudimentary understanding of how individual genes may contribute to create a phenotype more prone to develop AKI. Furthermore, none of these studies combined the prognostic information from genetic polymorphisms with existing predictive models. Because of these limitations to association studies, the next step in refining our understanding of at-risk genotypes will require large prospective studies of patients who develop AKI. The ideal model for such clinical studies will continue to be cardiac surgery for several reasons: this represents a high-volume surgical population, the epidemiology of AKI in this setting is well characterized, the timing of the injury is measurable, and improved risk prediction may translate into definable management strategies in the future [161].

\section{New 'OMICS' technologies and AKI}

'Omic' technologies (e.g. proteomics, metabolomics, exomes, etc.) should give researchers a holistic view of the molecules that are expressed (or overexpressed) in both physiological and pathological conditions [169-171]. These new technologies can be applied not only for a better 
understanding of normal physiological processes but also in pathological processes where they can play a role in the screening, diagnosis and prognosis as well as in aiding our understanding of the etiology of the diseases. The application of metabolomics, proteomics and functional genomics to evaluate and monitor the presence of acute kidney disease is still under development [172-174]. Validation of these new biomarkers could provide additional tools to detect the onset and severity of kidney injury. Moreover, a significant opportunity exists to integrate metabolomic and proteomic analyses in the study of renal pathophysiology [171, 172]. Several new metabolites [175-178] and exomes [179-181] have been proposed as biomarkers of AKI both in animal and human models. Future work is needed to focus on unambiguous identification of metabolite biomarkers and extensive validation efforts to put these markers to good use for early disease diagnosis in clinical practice [171].

\section{Conclusion}

Acute kidney injury is a very dangerous complication. It is associated with an increased risk of mortality and morbidity, and longer hospital stay, requires additional treatment, and increases the costs of the heath care. This clinical syndrome is characterized by a progressively worsening course, being the consequence of an interplay of different pathophysiologic mechanisms. Several different factors, like hemodynamic or inflammatory status, genetic background and use of nephrotoxic compound, are all involved. Unfortunately, the heterogeneity of AKI subtypes poses a great limit for large population studies in human subjects. In this setting, the use of classic clinical predictive models associated with novel renal biomarkers (both biological and genetic) may well be the only way to refine the methods of treatment and improve the prognosis of patients. Introduction of novel independent biomarkers of AKI into the clinical setting is crucial for earlier diagnosis and improved risk assessment. The purpose of this review was to help clarify the biological basis of new AKI biomarkers that might contribute to improving the early detection or diagnosis of this pathology. But before biomarkers can be advocated for the diagnosis of AKI, further research is needed. Our understanding of how to prevent and manage AKI in an optimal way requires additional effort.

Acknowledgements Thanks to Dr. Giancarlo Joli and to Ms. Cinzia Scotti for English revision and technical support.

Author contributions The authors contributed equally to researching data for the article, discussion of its content, writing and reviewing and/or editing of the manuscript before submission.

\section{Compliance with ethical standards}

\section{Conflict of interest None.}

Ethical approval This article does not contain any studies with human participants performed by any of the authors.

Open Access This article is distributed under the terms of the Creative Commons Attribution 4.0 International License (http:// creativecommons.org/licenses/by/4.0/), which permits unrestricted use, distribution, and reproduction in any medium, provided you give appropriate credit to the original author(s) and the source, provide a link to the Creative Commons license, and indicate if changes were made.

\section{References}

1. Hoste EA, Kellum JA (2004) Acute renal failure in the critically ill: impact on morbidity and mortality. Contrib Nephrol 144:1-11

2. Chertow GM, Levy EM, Hammermeister KE et al (1998) Independent association between acute renal failure and mortality following cardiac surgery. Am J Med 104:343-348

3. KDIGO (2012) KDIGO clinical practice guideline for acute kidney injury. Kidney Int 2:1-141. doi:10.1038/kisup.2012.1

4. Lieske JC, Chawla L, Kashani K et al (2014) Biomarkers for acute kidney injury: where are we today? Where should we go? Clin Chem 60:294-300. doi:10.1373/clinchem.2012.201988

5. Murray PT, Mehta RL, Shaw A et al (2013) Potential use of biomarkers in acute kidney injury: report and summary of recommendations from the 10th acute dialysis quality initiative consensus conference. Kidney Int 85:513-521. doi:10.1038/ ki.2013.374

6. Coca SG, Yalavarthy R, Concato J, Parikh CR (2008) Biomarkers for the diagnosis and risk stratification of acute kidney injury: a systematic review. Kidney Int 73:1008-1016. doi:10.1038/sj.ki.5002729

7. Huen SC, Parikh CR (2012) Predicting acute kidney injury after cardiac surgery: a systematic review. Ann Thorac Surg 93:337347. doi:10.1016/j.athoracsur.2011.09.010

8. Vaidya VS, Ferguson MA, Bonventre JV (2008) Biomarkers of acute kidney injury. Annu Rev Pharmacol Toxicol 48:463-493. doi:10.1146/annurev.pharmtox.48.113006.094615

9. Borregaard N, Sehested M, Nielsen BS et al (1995) Biosynthesis of granule proteins in normal human bone marrow cells. Gelatinase is a marker of terminal neutrophil differentiation. Blood 85:812-817

10. Nielsen BS, Borregaard N, Bundgaard JR et al (1996) Induction of NGAL synthesis in epithelial cells of human colorectal neoplasia and inflammatory bowel diseases. Gut 38:414-420

11. Cruz DN, de Cal M, Garzotto F et al (2010) Plasma neutrophil gelatinase-associated lipocalin is an early biomarker for acute kidney injury in an adult ICU population. Intensive Care Med 36:444-451. doi:10.1007/s00134-009-1711-1

12. Mishra J, Ma Q, Prada A et al (2003) Identification of neutrophil gelatinase-associated lipocalin as a novel early urinary biomarker for ischemic renal injury. J Am Soc Nephrol $14: 2534-2543$

13. Mori K, Lee HT, Rapoport D et al (2005) Endocytic delivery of lipocalin-siderophore-iron complex rescues the kidney from ischemia-reperfusion injury. J Clin Invest 115:610-621. doi:10.1172/JCI23056 
14. Berger T, Togawa A, Duncan GS et al (2006) Lipocalin 2-deficient mice exhibit increased sensitivity to Escherichia coli infection but not to ischemia-reperfusion injury. Proc Natl Acad Sci USA 103:1834-1839. doi:10.1073/ pnas.0510847103

15. Devarajan P (2010) Neutrophil gelatinase-associated lipocalin: a promising biomarker for human acute kidney injury. Biomark Med 4:265-280. doi:10.2217/bmm.10.12

16. Mishra J, Mori K, Ma Q et al (2004) Neutrophil gelatinase-associated lipocalin: a novel early urinary biomarker for cisplatin nephrotoxicity. Am J Nephrol 24:307-315. doi: $10.1159 / 000078452$

17. Mishra J, Dent C, Tarabishi R et al (2005) Neutrophil gelatinase-associated lipocalin (NGAL) as a biomarker for acute renal injury after cardiac surgery. The Lancet 365:1231-1238. doi:10.1016/S0140-6736(05)74811-X

18. Wagener G, Jan M, Kim M et al (2006) Association between increases in urinary neutrophil gelatinase-associated lipocalin and acute renal dysfunction after adult cardiac surgery. Anesthesiology 105:485-491

19. Ronco C (2014) Biomarkers for acute kidney injury: is NGAL ready for clinical use? Crit Care 18:680. doi:10.1186/ s13054-014-0680-0

20. Ronco C, Legrand M, Goldstein SL et al (2014) Neutrophil gelatinase-associated lipocalin: ready for routine clinical use? An international perspective. Blood Purif 37:271-285. doi:10.1159/000360689

21. Haase M, Bellomo R, Devarajan P et al (2009) Accuracy of neutrophil gelatinase-associated lipocalin (NGAL) in diagnosis and prognosis in acute kidney injury: a systematic review and meta-analysis. Am J Kidney Dis 54:1012-1024. doi:10.1053/j. ajkd.2009.07.020

22. Peacock WF, Maisel A, Kim J, Ronco C (2013) Neutrophil gelatinase associated lipocalin in acute kidney injury. Postgrad Med 125:82-93. doi:10.3810/pgm.2013.11.2715

23. de Geus HRH, Ronco C, Haase M et al (2016) The cardiac surgery-associated neutrophil gelatinase-associated lipocalin (CSA-NGAL) score: a potential tool to monitor acute tubular damage. J Thorac Cardiovasc Surg 151:1476-1481. doi:10.1016/j.jtcvs.2016.01.037

24. Cruz DN, Soni S, Ronco C (2009) NGAL and cardiac surgeryassociated acute kidney injury. Am J Kidney Dis 53:565-566. doi:10.1053/j.ajkd.2009.01.008

25. Shaw A (2012) Update on acute kidney injury after cardiac surgery. J Thorac Cardiovasc Surg 143:676-681. doi:10.1016/j. jtcvs.2011.08.054

26. Haase M, Haase-Fielitz A, Bellomo R, Mertens PR (2010) Neutrophil gelatinase-associated lipocalin as a marker of acute renal disease. Curr Opin Hematol. doi:10.1097/ MOH.0b013e3283411517

27. Nickolas TL, O'Rourke MJ, Yang J et al (2008) Sensitivity and specificity of a single emergency department measurement of urinary neutrophil gelatinase-associated lipocalin for diagnosing acute kidney injury. Ann Intern Med 148:810-819

28. Bignami E, Frati E, Meroni R et al (2015) Urinary neutrophil gelatinase-associated lipocalin time course during cardiac surgery. Ann Card Anaesth 18:39-44. doi:10.4103/0971-9784.148320

29. Stanhope R, Brook CC (1990) Thelarche variant: a new syndrome of precocious sexual maturation? Acta Endocrinol 123:481-486

30. Shlipak MG, Sarnak MJ, Katz R et al (2005) Cystatin C and the risk of death and cardiovascular events among elderly persons. N Engl J Med 352:2049-2060. doi:10.1056/NEJMoa043161

31. Shlipak MG, Wassel Fyr CL, Chertow GM et al (2006) Cystatin $\mathrm{C}$ and mortality risk in the elderly: the health, aging, and body composition study. J Am Soc Nephrol 17:254-261. doi:10.1681/ASN.2005050545

32. Bökenkamp A, Ciarimboli G, Dieterich C (2001) Cystatin C in a rat model of end-stage renal failure. Ren Fail 23:431-438

33. Uchida K, Gotoh A (2002) Measurement of cystatin-C and creatinine in urine. Clin Chim Acta 323:121-128

34. Conti M, Moutereau S, Zater M et al (2006) Urinary cystatin $\mathrm{C}$ as a specific marker of tubular dysfunction. Clin Chem Lab Med 44:288-291. doi:10.1515/CCLM.2006.050

35. Herget-Rosenthal S, Pietruck F, Volbracht L et al (2005) Serum cystatin C: a superior marker of rapidly reduced glomerular filtration after uninephrectomy in kidney donors compared to creatinine. Clin Nephrol 64:41-46

36. Koyner JL, Bennett MR, Worcester EM et al (2008) Urinary cystatin $\mathrm{C}$ as an early biomarker of acute kidney injury following adult cardiothoracic surgery. Kidney Int 74:1059-1069. doi:10.1038/ki.2008.341

37. Dharnidharka VR, Kwon C, Stevens G (2002) Serum cystatin C is superior to serum creatinine as a marker of kidney function: a meta-analysis. Am J Kidney Dis 40:221-226. doi:10.1053/ ajkd.2002.34487

38. Roos JF, Doust J, Tett SE, Kirkpatrick CMJ (2007) Diagnostic accuracy of cystatin $\mathrm{C}$ compared to serum creatinine for the estimation of renal dysfunction in adults and children: a meta-analysis. Clin Biochem 40:383-391. doi:10.1016/j. clinbiochem.2006.10.026

39. Herget-Rosenthal S, Bökenkamp A, Hofmann W (2007) How to estimate GFR-serum creatinine, serum cystatin C or equations? Clin Biochem 40:153-161. doi:10.1016/j. clinbiochem.2006.10.014

40. Séronie-Vivien S, Delanaye P, Piéroni L et al (2008) Cystatin C: current position and future prospects. Clin Chem Lab Med 46:1664-1686. doi:10.1515/CCLM.2008.336

41. Spahillari A, Parikh CR, Sint K et al (2012) Serum cystatin $\mathrm{C}$-versus creatinine-based definitions of acute kidney injury following cardiac surgery: a prospective cohort study. Am J Kidney Dis 60:922-929. doi:10.1053/j.ajkd.2012.06.002

42. Royakkers AANM, Korevaar JC, van Suijlen JDE et al (2011) Serum and urine cystatin $\mathrm{C}$ are poor biomarkers for acute kidney injury and renal replacement therapy. Intensive Care Med 37:493-501. doi:10.1007/s00134-010-2087-y

43. Charlton JR, Portilla D, Okusa MD (2014) A basic science view of acute kidney injury biomarkers. Nephrol Dial Transplant 29:1301-1311. doi:10.1093/ndt/gft510

44. Ichimura T, Bonventre JV, Bailly V et al (1998) Kidney injury molecule-1 (KIM-1), a putative epithelial cell adhesion molecule containing a novel immunoglobulin domain, is up-regulated in renal cells after injury. J Biol Chem 273:4135-4142

45. Han WK, Bailly V, Abichandani R et al (2002) Kidney injury molecule-1 (KIM-1): a novel biomarker for human renal proximal tubule injury. Kidney Int 62:237-244. doi:10.1046/j.1523-1755.2002.00433.x

46. Vaidya VS, Ramirez V, Ichimura T et al (2006) Urinary kidney injury molecule-1: a sensitive quantitative biomarker for early detection of kidney tubular injury. Am J Physiol Renal Physiol 290:F517-F529. doi:10.1152/ajprenal.00291.2005

47. Ichimura T, Hung CC, Yang SA et al (2004) Kidney injury molecule-1: a tissue and urinary biomarker for nephrotoxicantinduced renal injury. Am J Physiol Renal Physiol 286:F552F563. doi:10.1152/ajprenal.00285.2002

48. Huang Y, Don-Wauchope AC (2011) The clinical utility of kidney injury molecule 1 in the prediction, diagnosis and prognosis of acute kidney injury: a systematic review. Inflamm Allergy Drug Targets 10:260-271

49. Liangos O, Perianayagam MC, Vaidya VS et al (2007) Urinary $\mathrm{N}$-acetyl-beta-(D)-glucosaminidase activity and kidney 
injury molecule-1 level are associated with adverse outcomes in acute renal failure. J Am Soc Nephrol 18:904-912. doi:10.1681/ASN.2006030221

50. Koyner JL, Vaidya VS, Bennett MR et al (2010) Urinary biomarkers in the clinical prognosis and early detection of acute kidney injury. Clin J Am Soc Nephrol 5:2154-2165. doi:10.2215/CJN.00740110

51. Nakamura K, Okamura H, Nagata K et al (1993) Purification of a factor which provides a costimulatory signal for gamma interferon production. Infect Immun 61:64-70

52. Sugawara I (2000) Interleukin-18 (IL-18) and infectious diseases, with special emphasis on diseases induced by intracellular pathogens. Microbes Infect 2:1257-1263

53. Leslie JA, Meldrum KK (2008) The role of interleukin-18 in renal injury. J Surg Res 145:170-175. doi:10.1016/j. jss.2007.03.037

54. Parikh CR, Jani A, Melnikov VY et al (2004) Urinary interleukin-18 is a marker of human acute tubular necrosis. Am J Kidney Dis 43:405-414

55. Parikh CR, Mishra J, Thiessen-Philbrook H et al (2006) Urinary IL-18 is an early predictive biomarker of acute kidney injury after cardiac surgery. Kidney Int 70:199-203. doi:10.1038/sj.ki.5001527

56. Parikh CR, Abraham E, Ancukiewicz M, Edelstein CL (2005) Urine IL-18 is an early diagnostic marker for acute kidney injury and predicts mortality in the intensive care unit. J Am Soc Nephrol 16:3046-3052. doi:10.1681/ASN.2005030236

57. Glatz JF, van der Vusse GJ (1996) Cellular fatty acid-binding proteins: their function and physiological significance. Prog Lipid Res 35:243-282

58. Maatman RG, Van de Westerlo EM, van Kuppevelt TH (1992) Molecular identification of the liver-and the heart-type fatty acid-binding proteins in human and rat kidney. Use of the reverse transcriptase polymerase chain reaction. Biochem J 288:285-290

59. Maatman RG, van Kuppevelt TH, Veerkamp JH (1991) Two types of fatty acid-binding protein in human kidney. Isolation, characterization and localization. Biochem J 273:759-766

60. Sweetser DA, Heuckeroth RO, Gordon JI (1987) The metabolic significance of mammalian fatty-acid-binding proteins: abundant proteins in search of a function. Annu Rev Nutr 7:337-359. doi:10.1146/annurev.nu.07.070187.002005

61. Kamijo A, Kimura K, Sugaya $T$ et al (2004) Urinary fatty acid-binding protein as a new clinical marker of the progression of chronic renal disease. J Lab Clin Med 143:23-30. doi:10.1016/S0022214303001872

62. Kamijo A, Sugaya T, Hikawa A et al (2006) Urinary livertype fatty acid binding protein as a useful biomarker in chronic kidney disease. Mol Cell Biochem 284:175-182. doi:10.1007/s11010-005-9047-9

63. Negishi K, Noiri E, Sugaya T et al (2007) A role of liver fatty acid-binding protein in cisplatin-induced acute renal failure. Kidney Int 72:348-358. doi:10.1038/sj.ki.5002304

64. Kamijo A, Sugaya T, Hikawa A et al (2004) Urinary excretion of fatty acid-binding protein reflects stress overload on the proximal tubules. Am J Pathol 165:1243-1255. doi:10.1016/ S0002-9440(10)63384-6

65. Nakamura T, Sugaya T, Ebihara I, Koide H (2005) Urinary liver-type fatty acid-binding protein: discrimination between IgA nephropathy and thin basement membrane nephropathy. Am J Nephrol 25:447-450. doi:10.1159/000087826

66. Nakamura T, Sugaya T, Node K et al (2006) Urinary excretion of liver-type fatty acid-binding protein in contrast medium-induced nephropathy. Am J Kidney Dis 47:439-444. doi:10.1053/j.ajkd.2005.11.006
67. Price PM, Safirstein RL, Megyesi J (2009) The cell cycle and acute kidney injury. Kidney Int 76:604-613. doi:10.1038/ ki.2009.224

68. Boonstra J, Post JA (2004) Molecular events associated with reactive oxygen species and cell cycle progression in mammalian cells. Gene 337:1-13. doi:10.1016/j.gene.2004.04.032

69. Seo D-W, Li H, Qu C-K et al (2006) Shp-1 mediates the antiproliferative activity of tissue inhibitor of metalloproteinase-2 in human microvascular endothelial cells. J Biol Chem 281:3711-3721. doi:10.1074/jbc.M509932200

70. Rodier F, Campisi J, Bhaumik D (2007) Two faces of p53: aging and tumor suppression. Nucleic Acids Res 35:74757484. doi:10.1093/nar/gkm744

71. Yang Q-H, Liu D-W, Long Y et al (2009) Acute renal failure during sepsis: potential role of cell cycle regulation. J Infect 58:459-464. doi:10.1016/j.jinf.2009.04.003

72. Seo D-W, Li H, Guedez L et al (2003) TIMP-2 mediated inhibition of angiogenesis: an MMP-independent mechanism. Cell 114:171-180

73. Wajapeyee N, Serra RW, Zhu X et al (2008) Oncogenic BRAF induces senescence and apoptosis through pathways mediated by the secreted protein IGFBP7. Cell 132:363-374. doi:10.1016/j.cell.2007.12.032

74. Kashani K, Al-Khafaji A, Ardiles T et al (2013) Discovery and validation of cell cycle arrest biomarkers in human acute kidney injury. Crit Care 17:R25. doi:10.1186/cc12503

75. Dostanic-Larson I, Van Huysse JW, Lorenz JN, Lingrel JB (2005) The highly conserved cardiac glycoside binding site of Na, K-ATPase plays a role in blood pressure regulation. Proc Natl Acad Sci USA 102:15845-15850. doi:10.1073/ pnas.0507358102

76. Sophocleous A, Elmatzoglou I, Souvatzoglou A (2003) Circulating endogenous digitalis-like factor(s) (EDLF) in man is derived from the adrenals and its secretion is ACTH-dependent. J Endocrinol Invest 26:668-674

77. Laredo J, Hamilton BP, Hamlyn JM (1995) Secretion of endogenous ouabain from bovine adrenocortical cells: role of the zona glomerulosa and zona fasciculata. Biochem Biophys Res Commun 212:487-493. doi:10.1006/bbrc.1995.1996

78. Wang H, Haas M, Liang M et al (2004) Ouabain assembles signaling cascades through the caveolar $\mathrm{Na}^{+} / \mathrm{K}^{+}$-ATPase. J Biol Chem 279:17250-17259. doi:10.1074/jbc.M313239200

79. Manunta P, Rogowski AC, Hamilton BP, Hamlyn JM (1994) Ouabain-induced hypertension in the rat: relationships among plasma and tissue ouabain and blood pressure. J Hypertens $12: 549-560$

80. Rossoni LV, Salaices M, Miguel M et al (2002) Ouabaininduced hypertension is accompanied by increases in endothelial vasodilator factors. AJP 283:H2110-H2118. doi:10.1152/ ajpheart.00454.2002

81. Xavier FE, Rossoni LV, Alonso MJ et al (2004) Ouabaininduced hypertension alters the participation of endothelial factors in alpha-adrenergic responses differently in rat resistance and conductance mesenteric arteries. Br J Pharmacol 143:215225. doi:10.1038/sj.bjp.0705919

82. Nagy G, Gaszner B, nyi ELA et al (2010) Selective association of endogenous ouabain with subclinical organ damage in treated hypertensive patients. J Hum Hypertens 25:122-129. doi:10.1038/jhh.2010.24

83. Villa L, Buono R, Ferrandi M et al (2016) Ouabain contributes to kidney damage in a rat model of renal ischemia-reperfusion injury. Int J Mol Sci 17:1728. doi:10.3390/ijms17101728

84. Bignami E, Casamassima N, Frati E et al (2013) Preoperative endogenous ouabain predicts acute kidney injury in cardiac surgery patients. Crit Care Med 41:744-755. doi:10.1097/ CCM.0b013e3182741599 
85. Harwood SM, Allen DA, Raftery MJ, Yaqoob MM (2003) Calpain is a mediator of myocardial injury in experimental uremia: is it activated by endogenous ouabain? Kidney Int Suppl 63:S177-S180. doi:10.1046/j.1523-1755.63.s84.48.x

86. Peltier J, Bellocq A, Perez J et al (2006) Calpain activation and secretion promote glomerular injury in experimental glomerulonephritis: evidence from calpastatin-transgenic mice. J Am Soc Nephrol 17:3415-3423. doi:10.1681/ ASN.2006050542

87. Matsui I, Ito T, Kurihara $\mathrm{H}$ et al (2007) Snail, a transcriptional regulator, represses nephrin expression in glomerular epithelial cells of nephrotic rats. Lab Invest 87:273-283. doi:10.1038/ labinvest. 3700518

88. Simonini M, Lanzani C, Bignami E et al (2014) A new clinical multivariable model that predicts postoperative acute kidney injury: impact of endogenous ouabain. Nephrol Dial Transplant 29:1696-1701. doi:10.1093/ndt/gfu200

89. Simonini M, Pozzoli S, Bignami E et al (2015) Endogenous ouabain: an old cardiotonic steroid as a new biomarker of heart failure and a predictor of mortality after cardiac surgery. Biomed Res Int 2015:714710-714793. doi:10.1155/2015/714793

90. Caccamo AE, Scaltriti M, Caporali A et al (2004) Cell detachment and apoptosis induction of immortalized human prostate epithelial cells are associated with early accumulation of a $45 \mathrm{kDa}$ nuclear isoform of clusterin. Biochem J 382:157-168. doi:10.1042/BJ20040158

91. Xie Y, Sakatsume M, Nishi S et al (2001) Expression, roles, receptors, and regulation of osteopontin in the kidney. Kidney Int 60:1645-1657. doi:10.1046/j.1523-1755.2001.00032.x

92. Yu Y, Jin H, Holder D et al (2010) Urinary biomarkers trefoil factor 3 and albumin enable early detection of kidney tubular injury. Nat Biotechnol 28:470-477. doi:10.1038/nbt0.1624

93. Campbell JA, Corrigall AV, Guy A, Kirsch RE (1991) Immunohistologic localization of alpha, mu, and pi class glutathione S-transferases in human tissues. Cancer 67:1608-1613

94. Shu K-H, Wang C-H, Wu C-H et al (2016) Urinary $\pi$-glutathione $\mathrm{S}$-transferase predicts advanced acute kidney injury following cardiovascular surgery. Sci Rep 6:26335. doi:10.1038/srep26335

95. Cheon JH, Kim SY, Son JY et al (2016) Pyruvate kinase M2: a novel biomarker for the early detection of acute kidney injury. Toxicol Res 32:47-56. doi:10.5487/TR.2016.32.1.047

96. Malyszko J, Malyszko JS, Bachorzewska-Gajewska $\mathrm{H}$ et al (2009) Neutrophil gelatinase-associated lipocalin is a new and sensitive marker of kidney function in chronic kidney disease patients and renal allograft recipients. Transplant Proc 41:158161. doi:10.1016/j.transproceed.2008.10.088

97. Ding H, He Y, Li K et al (2007) Urinary neutrophil gelatinaseassociated lipocalin (NGAL) is an early biomarker for renal tubulointerstitial injury in IgA nephropathy. Clin Immunol 123:227-234. doi:10.1016/j.clim.2007.01.010

98. Bolignano D, Coppolino G, Campo S et al (2007) Neutrophil gelatinase-associated lipocalin in patients with autosomaldominant polycystic kidney disease. Am J Nephrol 27:373-378. doi:10.1159/000103912

99. Viau A, Karoui El K, Laouari D et al (2010) Lipocalin 2 is essential for chronic kidney disease progression in mice and humans. J Clin Invest 120:4065-4076. doi:10.1172/JCI42004

100. Waanders F, Vaidya VS, van Goor H et al (2009) Effect of renin-angiotensin-aldosterone system inhibition, dietary sodium restriction, and/or diuretics on urinary kidney injury molecule 1 excretion in nondiabetic proteinuric kidney disease: a post hoc analysis of a randomized controlled trial. Am J Kidney Dis 53:16-25. doi:10.1053/j.ajkd.2008.07.021

101. Sabbisetti VS, Waikar SS, Antoine DJ et al (2014) Blood kidney injury molecule- 1 is a biomarker of acute and chronic kidney injury and predicts progression to ESRD in type I diabetes. J Am Soc Nephrol 25:2177-2186. doi:10.1681/ASN.2013070758

102. Humphreys BD, Xu F, Sabbisetti V et al (2013) Chronic epithelial kidney injury molecule-1 expression causes murine kidney fibrosis. J Clin Invest 123:4023-4035. doi:10.1172/JCI45361

103. Kamijo A, Sugaya T, Hikawa A et al (2005) Clinical evaluation of urinary excretion of liver-type fatty acid-binding protein as a marker for the monitoring of chronic kidney disease: a multicenter trial. J Lab Clin Med 145:125-133

104. Nielsen SE, Sugaya T, Hovind P et al (2010) Urinary liver-type fatty acid-binding protein predicts progression to nephropathy in type 1 diabetic patients. Diabetes Care 33:1320-1324. doi: $10.2337 / \mathrm{dc} 09-2242$

105. Shlipak MG, Katz R, Sarnak MJ et al (2006) Cystatin C and prognosis for cardiovascular and kidney outcomes in elderly persons without chronic kidney disease. Ann Intern Med 145:237-246

106. Bagshaw SM, Bellomo R (2010) Cystatin C in acute kidney injury. Curr Opin Crit Care 16:533-539. doi:10.1097/ MCC.0b013e32833e8412

107. Herget-Rosenthal S, Marggraf G, Hüsing J et al (2004) Early detection of acute renal failure by serum cystatin C. Kidney Int 66:1115-1122. doi:10.1111/j.1523-1755.2004.00861.x

108. MD JH, PhD NTM, MD PK et al (2015) Urinary, plasma, and serum biomarkers' utility for predicting acute kidney injury associated with cardiac surgery in adults: a meta-analysis. Am J Kidney Dis. doi:10.1053/j.ajkd.2015.06.018

109. Delcroix G, Gillain N, Moonen M et al (2013) NGAL usefulness in the intensive care unit three hours after cardiac surgery. ISRN Nephrol 2013:865164-865166. doi:10.5402/2013/865164

110. Medić B, Rovčanin B, Basta Jovanović G et al (2015) Kidney injury molecule-1 and cardiovascular diseases: from basic science to clinical practice. Biomed Res Int 2015:854010-854070. doi:10.1155/2015/854070

111. Hassinger AB, Backer CL, Lane JC et al (2012) Predictive power of serum cystatin $\mathrm{C}$ to detect acute kidney injury and pediatric-modified RIFLE class in children undergoing cardiac surgery. Pediatr Crit Care Med 13:435-440. doi:10.1097/ PCC.0b013e318238b43c

112. Mårtensson J, Bell M, Oldner A et al (2010) Neutrophil gelatinase-associated lipocalin in adult septic patients with and without acute kidney injury. Intensive Care Med 36:1333-1340. doi:10.1007/s00134-010-1887-4

113. Chawla LS (2012) Disentanglement of the acute kidney injury syndrome. Curr Opin Crit Care 18:579-584. doi:10.1097/ MCC.0b013e328358e59c

114. Zhang Z (2015) Biomarkers, diagnosis and management of sepsis-induced acute kidney injury: a narrative review. Heart Lung Vessel 7:64-73

115. Schrier RW, Wang W (2004) Acute renal failure and sepsis. N Engl J Med 351:159-169. doi:10.1056/NEJMra032401

116. Suh SH, Kim CS, Choi JS et al (2013) Acute kidney injury in patients with sepsis and septic shock: risk factors and clinical outcomes. Yonsei Med J 54:965-972. doi:10.3349/ ymj.2013.54.4.965

117. Alobaidi R, Basu RK, Goldstein SL, Bagshaw SM (2015) Sepsis-associated acute kidney injury. Semin Nephrol 35:2-11. doi:10.1016/j.semnephrol.2015.01.002

118. Bagshaw SM, Bennett M, Devarajan P, Bellomo R (2013) Urine biochemistry in septic and non-septic acute kidney injury: a prospective observational study. J Crit Care 28:371-378. doi:10.1016/j.jcrc.2012.10.007

119. Bagshaw SM, Langenberg C, Bellomo R (2006) Urinary biochemistry and microscopy in septic acute renal failure: a systematic review. Am J Kidney Dis 48:695-705. doi:10.1053/j. ajkd.2006.07.017 
120. Bagshaw SM, Langenberg C, Wan L et al (2007) A systematic review of urinary findings in experimental septic acute renal failure. Crit Care Med 35:1592-1598. doi:10.1097/01. CCM.0000266684.17500.2F

121. Bagshaw SM, Bennett M, Haase M et al (2010) Plasma and urine neutrophil gelatinase-associated lipocalin in septic versus non-septic acute kidney injury in critical illness. Intensive Care Med 36:452-461. doi:10.1007/s00134-009-1724-9

122. Kim H, Hur M, Cruz DN et al (2013) Plasma neutrophil gelatinase-associated lipocalin as a biomarker for acute kidney injury in critically ill patients with suspected sepsis. Clin Biochem 46:1414-1418. doi:10.1016/j.clinbiochem.2013.05.069

123. Tu Y, Wang H, Sun R et al (2014) Urinary netrin-1 and KIM-1 as early biomarkers for septic acute kidney injury. Ren Fail 36:1559-1563. doi:10.3109/0886022X.2014.949764

124. Powell TC, Powell SL, Allen BK et al (2014) Association of inflammatory and endothelial cell activation biomarkers with acute kidney injury after sepsis. Springerplus 3:207. doi:10.1186/2193-1801-3-207

125. Zhang Z, Lu B, Ni $\mathrm{H}$ et al (2013) Microalbuminuria can predict the development of acute kidney injury in critically ill septic patients. J Nephrol 26:724-730. doi:10.5301/ jn.5000231

126. Vanmassenhove J, Glorieux G, Lameire $N$ et al (2015) Influence of severity of illness on neutrophil gelatinase-associated lipocalin performance as a marker of acute kidney injury: a prospective cohort study of patients with sepsis. BMC Nephrol 16:18. doi:10.1186/s12882-015-0003-y

127. Murase K, Mori K, Yoshimura C et al (2013) Association between plasma neutrophil gelatinase associated lipocalin level and obstructive sleep apnea or nocturnal intermittent hypoxia. PLoS ONE 8:e54184. doi:10.1371/journal.pone.0054184

128. Koyner JL, Davison DL, Brasha-Mitchell E et al (2015) Furosemide stress test and biomarkers for the prediction of AKI severity. J Am Soc Nephrol. doi:10.1681/ASN.2014060535

129. Chawla LS, Davison DL, Brasha-Mitchell E et al (2013) Development and standardization of a furosemide stress test to predict the severity of acute kidney injury. Crit Care 17:R207. doi:10.1186/cc13015

130. Molina E, Herrera J, Rodríguez-Iturbe B (1988) The renal functional reserve in health and renal disease in school age children. Kidney Int 34:809-816

131. Radermacher L, Godon JP (1992) Renal functional reserve. Acta Clin Belg 47:338-350

132. Thomas DM, Coles GA, Williams JD (1994) What does the renal reserve mean? Kidney Int 45:411-416

133. Sharma A, Mucino MJ, Ronco C (2014) Renal functional reserve and renal recovery after acute kidney injury. Nephron Clin Pract 127:94-100. doi:10.1159/000363721

134. Ronco C, Brendolan A, Bragantini L et al (1988) Renal functional reserve in pregnancy. Nephrol Dial Transplant 3:157-161

135. Bosch JP, Saccaggi A, Lauer A et al (1983) Renal functional reserve in humans. Effect of protein intake on glomerular filtration rate. Am J Med 75:943-950

136. Fliser D, Zeier M, Nowack R, Ritz E (1993) Renal functional reserve in healthy elderly subjects. J Am Soc Nephrol 3:1371-1377

137. Sharma A, Zaragoza JJ, Villa G et al (2016) Optimizing a kidney stress test to evaluate renal functional reserve. Clin Nephrol 86:18-26. doi:10.5414/CN108497

138. Pekkafalı MZ, Kara K (2015) Doppler ultrasound measurements of renal functional reserve in healthy subjects. Med Ultrason 17:464-468

139. Thakar CV (2010) Predicting acute kidney injury after cardiac surgery: how to use the "crystal ball". Am J Kidney Dis 56:605-608. doi:10.1053/j.ajkd.2010.07.005
140. Brown JR, Cochran RP, Leavitt BJ et al (2007) Multivariable prediction of renal insufficiency developing after cardiac surgery. Circulation 116:I139-I143. doi:10.1161/ CIRCULATIONAHA.106.677070

141. Chertow GM, Lazarus JM, Christiansen CL et al (1997) Preoperative renal risk stratification. Circulation 95:878-884

142. Thakar CV, Arrigain S, Worley S et al (2005) A clinical score to predict acute renal failure after cardiac surgery. J Am Soc Nephrol 16:162-168. doi:10.1681/ASN.2004040331

143. Mehta RH, Grab JD, O’Brien SM et al (2006) Bedside tool for predicting the risk of postoperative dialysis in patients undergoing cardiac surgery. Circulation 114:1226-2208. doi:10.1161/ CIRCULATIONAHA.106.635573 (quiz 2208)

144. Aronson S, Fontes ML, Miao Y et al (2007) Risk index for perioperative renal dysfunction/failure: critical dependence on pulse pressure hypertension. Circulation 115:733-742. doi:10.1161/ CIRCULATIONAHA.106.623538

145. Palomba H, de Castro I, Neto ALC et al (2007) Acute kidney injury prediction following elective cardiac surgery: AKICS Score. Kidney Int 72:624-631. doi:10.1038/sj.ki.5002419

146. Wijeysundera DN, Karkouti K, Dupuis J-Y et al (2007) Derivation and validation of a simplified predictive index for renal replacement therapy after cardiac surgery. JAMA 297:18011809. doi:10.1001/jama.297.16.1801

147. Mariscalco G, Lorusso R, Dominici C et al (2011) Acute kidney injury: a relevant complication after cardiac surgery. Ann Thorac Surg 92:1539-1547. doi:10.1016/j. athoracsur.2011.04.123

148. Goldstein SL, Chawla LS (2010) Renal Angina. Clin J Am Soc Nephrol 5:943-949. doi:10.2215/CJN.07201009

149. Ronco C, Ricci Z (2013) The concept of risk and the value of novel markers of acute kidney injury. Crit Care 17:117. doi: $10.1186 / \mathrm{cc} 12488$

150. Johnson XD, Liu KD (2010) Acute renal syndrome/renal angina: a new paradigm for studies of acute kidney injury? Clin J Am Soc Nephrol 5:753-755. doi:10.2215/CJN.02360310

151. Cruz DN, Ferrer-Nadal A, Piccinni P et al (2014) Utilization of small changes in serum creatinine with clinical risk factors to assess the risk of AKI in critically 111 adults. Clin J Am Soc Nephrol 9:663-672. doi:10.2215/CJN.05190513

152. Basu RK, Zappitelli M, Brunner L et al (2014) Derivation and validation of the renal angina index to improve the prediction of acute kidney injury in critically ill children. Kidney Int 85:659667. doi:10.1038/ki.2013.349

153. Chawla LS, Goldstein SL, Kellum JA, Ronco C (2015) Renal angina: concept and development of pretest probability assessment in acute kidney injury. Crit Care 19:93. doi:10.1186/ s13054-015-0779-y

154. Chawla LS, Abell L, Mazhari R et al (2005) Identifying critically ill patients at high risk for developing acute renal failure: a pilot study. Kidney Int 68:2274-2280. doi:10.1111/j.1523-1755.2005.00686.x

155. Stafford-Smith M, Podgoreanu M, Swaminathan M et al (2005) Association of genetic polymorphisms with risk of renal injury after coronary bypass graft surgery. Am J Kidney Dis 45:519530. doi:10.1053/j.ajkd.2004.11.021

156. Rider LG, Shamim E, Okada S et al (1999) Genetic risk and protective factors for idiopathic inflammatory myopathy in Koreans and American whites: a tale of two loci. Arthritis Rheum 42:1285-1290. doi:10.1002/15290131(199906)42:6<1285::AID-ANR28>3.0.CO;2-1

157. Lu JCT, Coca SG, Patel UD et al (2009) Searching for genes that matter in acute kidney injury: a systematic review. Clin J Am Soc Nephrol 4:1020-1031. doi:10.2215/CJN.05411008

158. Hudson C, Hudson J, Swaminathan $M$ et al (2008) Emerging concepts in acute kidney injury following 
cardiac surgery. Semin Cardiothorac Vasc Anesth 12:320-330. doi: $10.1177 / 1089253208328582$

159. Brull DJ, Montgomery HE, Sanders J et al (2001) Interleukin-6 gene $-174 \mathrm{~g}>\mathrm{c}$ and $-572 \mathrm{~g}>\mathrm{c}$ promoter polymorphisms are strong predictors of plasma interleukin-6 levels after coronary artery bypass surgery. Arterioscler Thromb Vasc Biol 21:1458-1463

160. Popov AF, Schulz EG, Schmitto JD et al (2010) Relation between renal dysfunction requiring renal replacement therapy and promoter polymorphism of the erythropoietin gene in cardiac surgery. Artif Organs 34:961-968. doi:10.1111/j.1525-1594.2010.01108.x

161. Depelchin P, Sobolski J, Jottrand M, Flament C (1988) Secondary prevention after myocardial infarction: effects of beta blocking agents and calcium antagonists. Cardiovasc Drugs Ther 2:139-148

162. Laffey JG, Boylan JF, Cheng DCH (2002) The systemic inflammatory response to cardiac surgery: implications for the anesthesiologist. Anesthesiology 97:215-252

163. Meldrum DR, Donnahoo KK (1999) Role of TNF in mediating renal insufficiency following cardiac surgery: evidence of a postbypass cardiorenal syndrome. J Surg Res 85:185-199. doi:10.1006/jsre. 1999.5660

164. Jaber BL, Rao M, Guo D et al (2004) Cytokine gene promoter polymorphisms and mortality in acute renal failure. Cytokine 25:212-219. doi:10.1016/j.cyto.2003.11.004

165. Isbir SC, Tekeli A, Ergen A et al (2007) Genetic polymorphisms contribute to acute kidney injury after coronary artery bypass grafting. Heart Surg Forum 10:E439-E444. doi:10.1532/ HSF98.20071117

166. Chew ST, Newman MF, White WD et al (2000) Preliminary report on the association of apolipoprotein E polymorphisms, with postoperative peak serum creatinine concentrations in cardiac surgical patients. Anesthesiology 93:325-331

167. Perianayagam MC, Liangos O, Kolyada AY et al (2007) NADPH oxidase p22phox and catalase gene variants are associated with biomarkers of oxidative stress and adverse outcomes in acute renal failure. J Am Soc Nephrol 18:255-263. doi:10.1681/ASN.2006070806

168. Luo HD, Ramirez SP, Costa MD et al (2004) Preoperative microalbuminuria, haptoglobin phenotype $2-2$, and age are independent predictors for acute renal failure following coronary artery bypass graft. Ann Acad Med Singap 33:S15-S16

169. Chambers JC, Zhang W, Lord GM et al (2010) Genetic loci influencing kidney function and chronic kidney disease. Nat Genet 42:373-375. doi:10.1038/ng.566
170. Mussap M, Noto A, Fanos V, Van Den Anker JN (2014) Emerging biomarkers and metabolomics for assessing toxic nephropathy and acute kidney injury (AKI) in neonatology. Biomed Res Int 2014:602516-602526. doi:10.1155/2014/602526

171. Weiss RH, Kim K (2011) Metabolomics in the study of kidney diseases. Nat Publ Group 8:22-33. doi:10.1038/ nrneph.2011.152

172. Portilla D, Schnackenberg L, Beger RD (2007) Metabolomics as an extension of proteomic analysis: study of acute kidney injury. Semin Nephrol 27:609-620. doi:10.1016/j. semnephrol.2007.09.006

173. Nicholson JK, Lindon JC, Holmes E (1999) "Metabonomics": understanding the metabolic responses of living systems to pathophysiological stimuli via multivariate statistical analysis of biological NMR spectroscopic data. Xenobiotica 29:11811189. doi:10.1080/004982599238047

174. Fiehn O (2002) Metabolomics: the link between genotypes and phenotypes. Plant Mol Biol 48:155-171

175. Boudonck KJ, Mitchell MW, Német L et al (2009) Discovery of metabolomics biomarkers for early detection of nephrotoxicity. Toxicol Pathol 37:280-292. doi:10.1177/0192623309332992

176. Xu EY, Perlina A, Vu H et al (2008) Integrated pathway analysis of rat urine metabolic profiles and kidney transcriptomic profiles to elucidate the systems toxicology of model nephrotoxicants. Chem Res Toxicol 21:1548-1561. doi:10.1021/ tx800061w

177. Melnick JZ, Baum M, Thompson JR (1994) Aminoglycosideinduced Fanconi's syndrome. Am J Kidney Dis 23:118-122

178. Uehara T, Horinouchi A, Morikawa Y et al (2014) Identification of metabolomic biomarkers for drug-induced acute kidney injury in rats. J Appl Toxicol 34:1087-1095. doi:10.1002/ jat.2933

179. Zhou H, Pisitkun T, Aponte A et al (2006) Exosomal Fetuin-A identified by proteomics: a novel urinary biomarker for detecting acute kidney injury. Kidney Int 70:1847-1857. doi:10.1038/ sj.ki.5001874

180. Panich T, Chancharoenthana W, Somparn P et al (2017) Urinary exosomal activating transcriptional factor 3 as the early diagnostic biomarker for sepsis-induced acute kidney injury. BMC Nephrol 18:10. doi:10.1186/s12882-016-0415-3

181. Alvarez S, Suazo C, Boltansky A et al (2013) Urinary exosomes as a source of kidney dysfunction biomarker in renal transplantation. Transplant Proc 45:3719-3723. doi:10.1016/j. transproceed.2013.08.079 